\title{
Temperature dependencies of the elastic moduli and thermal expansion coefficient of an equiatomic, single- phase CoCrFeMnNi high-entropy alloy
}

\author{
G. Laplanche ${ }^{\text {a,* }}$, P. Gadaud ${ }^{\text {b }}$, O. Horst ${ }^{\text {a }}$, F. Otto ${ }^{\text {a }}$, G. Eggeler ${ }^{\text {a }}$, E.P. George ${ }^{\text {a,c }}$ \\ ${ }^{a}$ Institut für Werkstoffe, Ruhr-Universitaet Bochum, D-44801 Bochum, Germany \\ b Institut P', CNRS-ENSMA-Université de Poitiers, UPR 3346, Département de Physique et \\ Mécanique des Matériaux, 1 Avenue Clément Ader, F-86961, Futuroscope Chasseneuil, \\ France \\ ${ }^{\mathrm{c}}$ Materials Science and Technology Division, Oak Ridge National Laboratory, Oak Ridge, \\ TN, USA
}

*corresponding author: Tel.: +49 (0)234 32 25912; fax: +49 (0)234 32 14235;

guillaume.laplanche@rub.de

\begin{abstract}
The equiatomic CoCrFeMnNi alloy is now regarded as a model face-centered cubic singlephase high-entropy alloy. Therefore, determination of its intrinsic properties such as the temperature dependencies of elastic moduli and thermal expansion coefficient are important to improve understanding of this new class of material. These temperature dependencies were measured over a large temperature range $(200-1270 \mathrm{~K})$ in this study.
\end{abstract}

Keywords: Metals and alloys; Entropy; Microstructure; Thermal expansion coefficient; Elasticity 


\section{Introduction}

High-entropy alloys (HEAs) were defined as alloys containing at least five major elements, each of which has a concentration ranging between 5 and 35 at.\% [1]. The term "highentropy" is based on the hypothesis that the high mixing entropy of these alloys can overcome the enthalpies of compound formation, i.e., favor the formation of a single solid solution phase at the expense of a multiphase microstructure including intermetallic or secondary solid solution phases. In spite of experimental results which proved that this assumption is not universally valid $[2,3]$, the term "high-entropy alloys" is now often used in the literature to describe all multi-principal-element alloys, even those that are multi-phase. Nevertheless, a few true single-phase body-centered cubic (BCC) [4-8], orthorhombic [9] and face-centered cubic (FCC) $[2,3,10,11]$ HEAs have been reported so far.

First reported by Cantor et al. [2], single-phase FCC HEAs based on the five elements $\mathrm{Co}, \mathrm{Cr}$, $\mathrm{Fe}, \mathrm{Mn}$ and $\mathrm{Ni}$ are receiving increasing attention in the scientific community. One reason for this is that CoCrFeMnNi HEAs have been shown to exhibit remarkable microstructural stability [3, 10, 12-15], i.e., they remain single-phase even after elevated temperature exposures of several days $[3,15]$. It is thus not surprising that among the various HEAs the $\mathrm{CoCrFeMnNi}$ solid solution alloy is the one on which the most fundamental mechanical characterizations have so far been conducted.

In its equiatomic form the $\mathrm{CoCrFeMnNi} \mathrm{HEA}$ has been reported to exhibit interesting mechanical properties, which might be intrinsic to certain sub-sets of single-phase HEAs. For example, in tensile tests the yield strength, ultimate tensile strength and elongation to fracture were found to simultaneously increase when the temperature was lowered from room temperature to $77 \mathrm{~K}[16,17]$. In a more recent study, very high fracture toughnesses were measured at $77 \mathrm{~K}$ for the same alloy [18]. These results are in sharp contrast to the behavior of 
most metals that usually show an inverse relationship between strength and ductility/toughness. Microstructural observations indicate that increases in the ultimate tensile strength, ductility and toughness are related to changes in the governing deformation mechanism from conventional dislocation plasticity at room temperature and above to nanotwinning at $77 \mathrm{~K}[17,18]$. The reason for the temperature-dependent yield stress is still unclear, although a recent study of equiatomic lower-order alloys based on the elements in the CoCrFeMnNi HEA suggests that it may be related to changes in the dislocation width with temperature [19]. It can, however, be ruled out that it originates from a variation in the shear modulus, which depends only weakly on temperature in the range between 55 and $300 \mathrm{~K}$ [20]. Although HEAs have been mentioned as potential candidates for high temperature applications due to their anticipated sluggish diffusion kinetics [21, 22], no attempt has yet been made to investigate the elastic properties of the equiatomic $\mathrm{CoCrFeMnNi}$ high-entropy alloy at temperatures above $300 \mathrm{~K}$. In the present study, we address this deficiency by measuring the Young's modulus and the shear modulus as a function of temperature in the range between 200 and $1000 \mathrm{~K}$, which will allow the flow stress of the equiatomic $\mathrm{CoCrFeMnNi} \mathrm{HEA}$ at elevated temperatures to be normalized by the variation in the shear modulus. In addition, we report results from dilatometry measurements recorded in the temperature range between 300 and $1270 \mathrm{~K}$. In combination with the elastic property assessments, knowledge of the thermal expansion behavior allows for a better estimation of thermally induced stresses in the CoCrFeMnNi solid solution alloy.

\section{Experimental methods}

\subsection{Material}


A $1 \mathrm{~kg}$ ingot of the equiatomic $\mathrm{CoCrFeMnNi}$ alloy was produced by vacuum induction melting using pure elements (purity $\geq 99.9$ wt.\%) as starting materials. Since Mn rapidly oxidizes in air, the Mn flakes were cleaned in an aqueous solution of nitric acid right before they were added to the other materials in the vacuum induction melter. Moreover, to compensate for the Mn loss by evaporation, $2 \mathrm{~g} \mathrm{Mn}$ were added prior to melting. Melting was performed using a Leybold Heraeus IS 1/III vacuum induction furnace operating at 5-20 kW in a high purity argon (Ar) atmosphere (99.998 vol.\%). Prior to melting, the walls of the mold were coated with a yttria slurry, the furnace was evacuated to 3 mbar and then backfilled with Ar to a pressure of 500 mbar. The raw materials were vacuum induction melted and cast into a cylindrical mold having a diameter of $40 \mathrm{~mm}$ and a height of $120 \mathrm{~mm}$. The cast ingot was sealed in an evacuated quartz tube and homogenized at $1470 \mathrm{~K}$ for $48 \mathrm{~h}$ followed by aircooling. The homogenized ingot was processed by means of rotary swaging using a four-die swaging machine of type HMP R6-4-120-21S (HMP Umformtechnik GmbH, Pforzheim, Germany). In seven steps, the diameter of the cylindrical ingot was reduced from 40 to 16.5 $\mathrm{mm}$. After the final reduction, the swaged material was subjected to a recrystallization heat treatment for one hour at $1170 \mathrm{~K}$ followed by air-cooling.

\subsection{Microstructure}

Metallographic specimens were taken from the recrystallized CoCrFeMnNi HEA with their surface normal parallel to the longitudinal axis of the cylindrical rod. Prior to microstructural investigations, the sample surfaces were ground and polished with $\mathrm{SiC}$ abrasive paper down to a grit size of $8 \mu \mathrm{m}$ and subsequently with diamond suspension down to $1 \mu \mathrm{m}$. A final polishing step was performed using a vibratory polisher (Buehler Vibromet 2) and colloidal silica with a particle size of $0.06 \mu \mathrm{m}$; long polishing times of up to $48 \mathrm{~h}$ were employed to remove all residual deformation from the near-surface regions. 
The phase characterization was carried out by X-ray diffraction using a PANalytical X'Pert Pro MRD diffractometer $\left(\mathrm{Cu} \mathrm{K} \alpha\right.$ radiation $\lambda=0.154 \mathrm{~nm} ; 2 \theta$-range from $20^{\circ}$ to $120^{\circ}$; step size $\Delta 2 \theta=0.006^{\circ}$; integration time $280 \mathrm{~s}$ ). Microstructural characterization was performed using a LEO 1530VP field emission gun scanning electron microscope equipped with an electron backscatter diffraction (EBSD) detector. The texture as well as the grain size were determined by EBSD at an accelerating voltage of $30 \mathrm{kV}$, a working distance of 11-15 mm and step sizes between 1 and $5 \mu \mathrm{m}$. Pattern analysis was performed using the TSL OIM Analysis software (version 6.2.0).

The chemical composition of the homogenized ingot was determined at a commercial analysis laboratory (Revierlabor GmbH, Essen, Germany) where the metallic elements were analyzed by means of X-ray fluorescence analysis (XRFA) while the oxygen, carbon and sulfur levels were measured using the inert gas fusion IR and the combustion IR absorption methods [23].

\subsection{Measurements of the coefficient of thermal expansion and elastic moduli}

Cylindrical samples with $4 \mathrm{~mm}$ diameter and $10 \mathrm{~mm}$ height along the longitudinal axis of the recrystallized cylindrical rod were electric discharge machined for thermal expansion tests by dilatometry from $300 \mathrm{~K}$ to $1270 \mathrm{~K}$ at a heating rate of $5 \mathrm{~K} \mathrm{~s}^{-1}$.

The elastic moduli of recrystallized CoCrFeMnNi rods were measured as a function of temperature between 200 and $1000 \mathrm{~K}$ following the ASTM E1876-01 standard test method. Two sample geometries (beams and plates) with a $30 \mathrm{~mm}$ gauge length along the longitudinal axis of the recrystallized cylindrical rod were fabricated using electric discharge machining and subsequently polished with SiC papers of successively finer grades from 14 to $4 \mu \mathrm{m}$. Beam samples with sizes of $30 \times 5 \times 1 \mathrm{~mm}^{3}$ and plate samples with sizes of $30 \times 12 \times 1.5$ $\mathrm{mm}^{3}$ were tested in bending and torsion modes, respectively. Young's modulus $E$ was determined using the resonant frequency technique in bending mode on the beam samples. In 
this technique, the samples are maintained by steel wires located at vibration nodes. Both excitation and detection are performed by an electrostatic device that measures the capacitance between the sample and the excitation electrode [24]. The tests were performed at a heating rate of $1 \mathrm{~K} \mathrm{~min}^{-1}$ under high vacuum $\left(10^{-4} \mathrm{~Pa}\right)$ at strain amplitude lower than $10^{-6}$. The bending resonance frequency $F_{B}$ was determined by sweeping the excitation frequency with a network analyzer in the $\mathrm{kHz}$ frequency range. Young's modulus $E$ was then calculated according to

$$
E=0.9464 \rho F_{B}{ }^{2} \frac{l_{B}{ }^{4}}{h_{B}{ }^{2}} U\left(\frac{e_{B}}{l_{B}}, v\right)
$$

where $\rho$ is the density $\left(7.9 \mathrm{~g} / \mathrm{cm}^{3}\right.$ measured at room temperature (RT)), $v$ is Poisson's ratio, and $e_{B}, l_{B}$ and $h_{B}$ are the beam thickness, gauge length and width, respectively. For our sample geometry, the correction factor $U\left(e_{B} / l_{B}, v\right)$ which slightly depends on $v$ is close to $1[25,26]$. The shear modulus $G$ was determined using torsional deformation of plates and was calculated using [27]:

$$
G=\rho F_{T}^{2} \frac{\left(h_{T}{ }^{2}+e_{T}{ }^{2}\right) l_{T}{ }^{2}}{\left(1-\frac{e_{T}}{\sqrt{3} h_{T}}\right) e_{T}{ }^{2}}
$$

where $F_{T}$ is the torsion resonance frequency, $e_{T}, l_{T}$ and $h_{T}$ are the thickness, gauge length and width of the plate samples, respectively. For measurements at high temperature, the calculated moduli can be corrected for thermal expansion effects according to the ASTM E1876-01 standard test method 
$M(T)=M\left(T_{0}\right)\left(\frac{F(T)}{F\left(T_{0}\right)}\right)^{2} \frac{1}{1+\alpha \Delta T}$

where $M(T)$ and $M\left(T_{0}\right)$ are the moduli (either Young's modulus $E$ or shear modulus $G$ ) at temperature $T$ and at RT, $T_{0}$, respectively. $F(T)$ and $F\left(T_{0}\right)$ are the resonant frequencies at temperature $T$ and $T_{0}$, respectively. $\alpha$ is the thermal expansion coefficient and $\Delta T$ is the temperature differential between the test temperature $T$ and RT.

\section{Results and discussion}

\subsection{Material}

The chemical composition of our alloy determined by XRFA, $\mathrm{Co}_{20.26} \mathrm{Cr}_{19.41} \mathrm{Fe}_{20.65} \mathrm{Mn}_{20.10} \mathrm{Ni}_{19.58}$ (composition in at.\%), is consistent with the targeted equiatomic composition, see Tab. 1. Additional EDX measurements along the length and across the diameter of the cylindrical rod show that the chemical composition is homogeneous at the level of the EDX detection limit (0.5 at.\%). During processing, HEAs can come into contact with carbon and oxygen. The uptake of carbon and oxygen in HEAs results in the precipitation of carbides and oxides, respectively [15, 28]. For the objectives of the present work it was important to produce materials with small amounts of carbon and oxygen, as shown in Tab. 1, to investigate the intrinsic properties of FCC single-phase CoCrFeMnNi HEAs. For comparison, the carbon level of low carbon steels is below 0.3 wt. $\%$ which is one order of magnitude higher than the carbon content of our HEA (0.03 wt.\%). Finally the sulfur content of our HEA (0.005 wt.\%) is also below the upper limit of 316L steels (0.01 wt.\%). 
A representative X-ray diffraction pattern of the swaged and recrystallized CoCrFeMnNi HEA is shown in Fig. 1a. The diffraction peaks indicate the presence of a single FCC phase with a lattice parameter $a=0.360 \mathrm{~nm}$. No additional peaks can be found which would indicate the presence of significant amounts of a secondary phase. The single-phase character is confirmed by EBSD results which are given in Figs. 1b-e. While these are relatively coarsescale observations that could miss small second-phase particles [29], TEM analysis of this composition had previously shown it to be single-phase even when examined at a much finer scale [17].

Fig. $1 \mathrm{~b}$ shows an inverse pole figure map of the recrystallized sample where the individual grains are colored according to their crystallographic orientation relative to the sample surface normal (the surface normal is parallel to the swaging directions, i.e., the long axis of the swaged rod). In Fig. 1b, equiaxed grains (grain size: $15 \pm 5 \mu \mathrm{m}$ ) containing annealing twins can be observed. Figs. 1c-e show (001), (011) and (111) pole figures calculated from the EBSD data. The pole density scale is shown on the right side of Fig. 1e where the orientation distribution function was normalized to express densities in multiples of a random distribution. The texture of the CoCrFeMnNi HEA is almost random, with a slight (111) fiber texture, indicated by a maximum pole density of $\sim 2.3$ times random (Fig. 1e). This slight texture obtained after swaging is similar to the texture observed after cold rolling, i.e., $<111>/$ RD which was attributed to the formation of annealing twins enhanced by the low stacking fault energy of the CoCrFeMnNi alloy [13].

\subsection{Thermal expansion}

Recently, van Bohemen [30] showed that the thermal expansion $\Delta L / L_{0}=\left(L-L_{0}\right) / L_{0}$, of austenitic steels can be satisfactorily fitted to an exponential temperature dependence in the temperature range $(100-1600 \mathrm{~K})$ : 


$$
\frac{\Delta L}{L_{0}}=\frac{L-L_{0}}{L_{0}}=\alpha_{H T} T+\alpha_{H T} \Theta_{D}\left(e^{-T / \Theta_{D}}-1\right)
$$

where $L$ is the sample length, $T$ is the temperature, $\Theta_{D}$ is the Debye temperature, $\alpha_{H T}$ is the value of the coefficient of thermal expansion $\alpha$ in the high temperature limit and $L_{0}$ is the sample length at $T=0 \mathrm{~K}$. The temperature dependence of $\Delta L / L_{0}$ of our CoCrFeMnNi HEA is shown in black in Fig. 2a. Using $L_{0}=9.975 \mathrm{~mm}, \alpha_{H T}=23.7 \times 10^{-6} \mathrm{~K}^{-1}$ and $\Theta_{D}=299 \mathrm{~K}$, an excellent fit is obtained between Eq. (4) and the experimental data. Fig. 2a clearly shows that $\Delta L / L_{0}$ is not linearly dependent on the temperature over the investigated temperature range from 300 to $1270 \mathrm{~K}$. This behavior is similar to that observed in FCC steels [30], as well as in other metals [31] where no phase transformation occurs in the investigated temperature range. The value of $\alpha$ as a function of temperature is shown in Fig. 2b (red curve) and is obtained by differentiation of Eq. (4):

$$
\alpha=\frac{d}{d T}\left(\frac{\Delta L}{L_{0}}\right)=\alpha_{H T}\left(1-e^{-T / \Theta_{D}}\right)
$$

In addition, literature values of $\alpha$ for FCC steels [30] measured by dilatometry are presented in Fig. 2b. It is worth noting that the temperature dependence of $\alpha$ of $\mathrm{CoCrFeMnNi} \mathrm{HEA}$ is very similar to that of FCC steels.

\subsection{Elastic properties}

The microstructural information presented in Fig. 1 is representative for samples that were used to measure Young's modulus $E$ and the shear modulus $G$. Fig. 3a shows $E$ and $G$ 
measured between 200 and $1000 \mathrm{~K}$ (black points) and those corrected for thermal expansion effects (red points) according to standard test methods ATSM E1876-01 using Eq. (3) and the thermal expansion coefficients given in Fig. 2b. The corrected data slightly deviate from the raw data with a maximum deviation of $1.5 \%$ at $1000 \mathrm{~K}$. In Fig. 3b, corrected moduli measured between 200 and $1000 \mathrm{~K}$ (red curve) are given together with measurements between 55 and $300 \mathrm{~K}$ (blue curve) which were recently reported by Haglund et al. [20]. The experimental errors, obtained from 3 sets of experiments are $\pm 4 \mathrm{GPa}$ and $\pm 1 \mathrm{GPa}$ for $E$ and $G$, respectively. At RT, the measured moduli are $E=203 \mathrm{GPa}$ and $G=81 \mathrm{GPa}$. The $E$ - and $G$ values at RT are in excellent agreement with those reported by Haglund et al. [20], Fig. $3 \mathrm{~b}$. Both $E$ and $G$ decrease monotonically with the slopes of the $E(\mathrm{~T})$ and $G(\mathrm{~T})$ curves becoming steeper towards higher temperatures, see Fig. 3b. The temperature dependence of Young's modulus is similar to what is obtained for paramagnetic materials where no phase transformation occurs over the investigated temperature range [32]. This behavior has been observed in several materials such as pure metals [32, 33], steels [34, 35], intermetallics [36, 37], quasicrystals [38, 39] and superalloys [40, 41].

The $E(\mathrm{~T})$ and $G(\mathrm{~T})$ curves can be fitted to the empirical equation proposed by Varshni [42]

$c_{i j}(T)=c_{i j}{ }^{0}-s /\left(\mathrm{e}^{t / T}-1\right)$

where $T$ is the temperature, $c_{i j}(T)$ the temperature dependence of an elastic modulus (e.g., $E$ or $G), c_{i j}{ }^{0}(T)$ an elastic modulus at $0 \mathrm{~K}$, and $s$ and $t$ are fitting parameters. Varshni [42] showed that Eq. (6) describes the temperature dependence of the elastic moduli of many materials. All the $E$ and $G$ data in Fig. 3b (literature data [20] and the experimental results of the present study) can be rationalized by fitting Eq. (6) using the method of least squares (black dashed lines in Fig. 3b). Good agreement was found for $G^{0}=85 \mathrm{GPa}, s=16 \mathrm{GPa}$ and $t=448 \mathrm{~K}$ for 
the shear modulus and $E^{0}=214 \mathrm{GPa}, s=35 \mathrm{GPa}$ and $t=416 \mathrm{~K}$ for the Young's modulus over the temperature range $55-1000 \mathrm{~K}$. Note that the fitted curve (black dashed line in Fig. 3b) reproduces well the temperature dependence of the two sets of data (literature data [20] and the experimental results of the present study). It is also worth mentioning that the moduli at 0 $\mathrm{K}$ (fitting parameters) determined in the present study are in good agreement with DFT calculations $G^{0}=86 \mathrm{GPa}$ and $E^{0}=207 \mathrm{GPa}$ reported by Zaddach et al. [43].

As the CoCrFeMnNi rod is nearly untextured (see Fig. 1), it can be considered as an elastically isotropic polycrystal. Therefore, Poisson's ratio $v$ and bulk modulus $K$ can be calculated using the following expressions

$$
v=-1+\frac{E}{2 G}
$$

$$
K=\frac{E G}{3(3 G-E)}
$$

Using Eqs. (7-8), the Poisson's ratio and bulk modulus are $v=0.25 \pm 0.1$ and $K=137 \pm 8$ $\mathrm{GPa}$ at room temperature.

The temperature dependence of the Young's modulus $E$ of the HEA is compared to those of the elemental constituents taken from the literature, i.e., pure $\mathrm{Co}, \mathrm{Fe}, \mathrm{Mn}, \mathrm{Ni}$ [32] and $\mathrm{Cr}$ [33] in Fig. 3c. Irregularities observed in the curves for pure metals correspond to phase transformations or ferromagnetic to paramagnetic transitions, for more details, see [32, 33]. Due to the large number of alloying elements in HEAs, a high degree of solid solution 
hardening has been hypothesized [1]. Recently, Wu et al. showed that hardness [14] and yield strength [19] are not related simply to the number of alloying elements in FCC solid solution; rather the nature of the added element also plays an important role in the hardening of equiatomic HEAs. In particular, Wu et al. [14] suggested that hardening effects in CoCrFeMnNi HEAs might be largely due to the modulus mismatch between $\mathrm{Cr}$ and the other elements. As shown in Fig. 3c, the large mismatch at room temperature in the Young's modulus of $\mathrm{Cr}$ and the other elements extends also to other temperatures from 200 to $1000 \mathrm{~K}$.

The reduced modulus $E / E^{0}$ where $E^{0}$ is the Young's modulus extrapolated to $0 \mathrm{~K}$ as a function of the reduced (or homologous) temperature (fraction of the melting point for pure metals and fraction of the solidus temperature for the CoCrFeMnNi HEA) is shown in Fig. 3d. Comparison of Figs. 3d and 3c shows that all the data in Fig 3c lie within a narrow scatter band in Fig. $3 \mathrm{~d}$ over the temperature range from 0 to 0.5 times the melting or solidus temperature. As for the pure constituent metals, the reduced modulus of the equiatomic HEA seems to be correlated to the melting or solidus temperature, i.e., the reduced modulus for all materials decreases linearly with the reduced temperature in the temperature ranges where no phase transformations or ferromagnetic to paramagnetic occurs, see Fig. 3c. It is worth noting that this effect has also been reported for the Ni-Mn system $[44,45]$. Thus, the temperature dependence of the Young's modulus of the CoCrFeMnNi HEA does not appear to be anomalous relative to other metals and alloys.

\section{Conclusion}

A 1-kg ingot of the equiatomic $\mathrm{CoCrFeMnNi}$ high-entropy alloy was produced by vacuum induction melting and drop casting. The as-cast material was homogenized at $1470 \mathrm{~K}$ for $48 \mathrm{~h}$ 
and the diameter of the ingot was subsequently reduced by swaging. After a diameter reduction of $60 \%$, the HEA rod was annealed at $1170 \mathrm{~K}$ for $1 \mathrm{~h}$. The recrystallized material is a single-phase solid solution with a FCC crystal structure and exhibits equiaxed grain microstructure (grain size: $15 \pm 5 \mu \mathrm{m}$ ) with a nearly random texture. Temperature dependencies of its coefficient of thermal expansion and elastic moduli were studied over a large temperature range $(200-1270 \mathrm{~K})$. From the experimental results presented in this paper, the following conclusions can be drawn:

(1) No discontinuities in the thermal expansion coefficient or elastic moduli indicative of obvious bulk phase transformations could be detected during heating from 200 to $1270 \mathrm{~K}$.

(2) The coefficient of thermal expansion $\alpha$ of FCC CoCrFeMnNi HEA is not linearly dependent on the temperature. This temperature dependence is similar to that of FCC steels: it increases monotonously from $15 \times 10^{-6} \mathrm{~K}^{-1}$ to $23 \times 10^{-6} \mathrm{~K}^{-1}$ between 300 and $1270 \mathrm{~K}$ and can be described using

$\alpha=23.7 \times 10^{-6}\left(1-\mathrm{e}^{-T / 299}\right)$

(3) At room temperature, the measured elastic moduli are:

- Young's modulus $E=203 \mathrm{GPa}$,

- Shear modulus $G=81 \mathrm{GPa}$,

- Bulk modulus $K=137 \mathrm{GPa}$,

- Poisson's ratio $v=0.25$.

(4) The change in the Young's and shear moduli with temperature reported by Haglund et al. [20] between $55 \mathrm{~K}$ and $300 \mathrm{~K}$ and in the present study between 200 and $1000 \mathrm{~K}$ can be described satisfactorily using the following equations:

$G=85-16 /\left(\mathrm{e}^{448 / \mathrm{T}}-1\right)$

$E=214-35 /\left(\mathrm{e}^{416 / \mathrm{T}}-1\right)$ 


\section{Acknowledgments}

GL and FO received funding from the Alexander von Humboldt Foundation and EPG from the Materials Sciences and Engineering Division, Basic Energy Sciences, US Department of Energy

\section{References}

[1] J.W. Yeh, S.K. Chen, S.J. Lin, J.Y. Gan, T.S. Chin, T.T. Shun, C.H. Tsau, S.Y. Chang, Advanced Engineering Materials, 6 (2004) 299-303.

[2] B. Cantor, I.T.H. Chang, P. Knight, A.J.B. Vincent, Materials Science and Engineering: A, 375-377 (2004) 213-218.

[3] F. Otto, Y. Yang, H. Bei, E.P. George, Acta Materialia, 61 (2013) 2628-2638.

[4] O.N. Senkov, G.B. Wilks, J.M. Scott, D.B. Miracle, Intermetallics, 19 (2011) 698-706.

[5] O.N. Senkov, J.M. Scott, S.V. Senkova, F. Meisenkothen, D.B. Miracle, C.F. Woodward, Journal of Materials Science, 47 (2012) 4062-4074.

[6] Y. Zou, S. Maiti, W. Steurer, R. Spolenak, Acta Materialia, 65 (2014) 85-97.

[7] Y.D. Wu, Y.H. Cai, T. Wang, J.J. Si, J. Zhu, Y.D. Wang, X.D. Hui, Materials Letters, 130 (2014) 277-280.

[8] J.P. Couzinié, G. Dirras, L. Perrière, T. Chauveau, E. Leroy, Y. Champion, I. Guillot, Materials Letters, 126 (2014) 285-287.

[9] L. Lilensten, J.P. Couzinié, L. Perrière, J. Bourgon, N. Emery, I. Guillot, Materials Letters, 132 (2014) 123-125. 
[10] M.J. Yao, K.G. Pradeep, C.C. Tasan, D. Raabe, Scripta Materialia, 72-73 (2014) 5-8.

[11] J.Y. He, W.H. Liu, H. Wang, Y. Wu, X.J. Liu, T.G. Nieh, Z.P. Lu, Acta Materialia, 62 (2014) 105-113.

[12] W.H. Liu, Y. Wu, J.Y. He, T.G. Nieh, Z.P. Lu, Scripta Materialia, 68 (2013) 526-529.

[13] P.P. Bhattacharjee, G.D. Sathiaraj, M. Zaid, J.R. Gatti, C. Lee, C.-W. Tsai, J.-W. Yeh, Journal of Alloys and Compounds, 587 (2014) 544-552.

[14] Z. Wu, H. Bei, F. Otto, G.M. Pharr, E.P. George, Intermetallics, 46 (2014) 131-140.

[15] F. Otto, N.L. Hanold, E.P. George, Intermetallics, 54 (2014) 39-48.

[16] A. Gali, E.P. George, Intermetallics, 39 (2013) 74-78.

[17] F. Otto, A. Dlouhý, C. Somsen, H. Bei, G. Eggeler, E.P. George, Acta Materialia, 61 (2013) 5743-5755.

[18] B. Gludovatz, A. Hohenwarter, D. Catoor, E.H. Chang, E.P. George, R.O. Ritchie, Science, 345 (2014) 1153-1158.

[19] Z. Wu, H. Bei, G.M. Pharr, E.P. George, Acta Materialia, 81 (2014) 428-441.

[20] A. Haglund, M. Koehler, D. Catoor, E.P. George, V. Keppens, accepted for publication in Intermetallics, (2015).

[21] K.Y. Tsai, M.H. Tsai, J.W. Yeh, Acta Materialia, 61 (2013) 4887-4897.

[22] J.Y. He, C. Zhu, D.Q. Zhou, W.H. Liu, T.G. Nieh, Z.P. Lu, Intermetallics, 55 (2014) 914.

[23] D.C. Harris, Quantitative chemical analysis, seventh rev. ed, Freeman, W.H., New York, 2007.

[24] P. Mazot, J. de Fouquet, J. Woirgard, J.P. Pautrot, J Phys IV, III (1992) 751-763.

[25] S. Spinner, T.W. Reichard, W.E. Tefft, Journal of Research of ASTM, 64A (1960) 147155.

[26] S. Spinner, W.E. Tefft, Journal of Research of ASTM, 65A (1961) 167-171. 
[27] P. Gadaud, X. Milhet, S. Pautrot, Materials Science and Engineering: A, 521-522 (2009) 303-306.

[28] T.-T. Shun, Y.-C. Du, Journal of Alloys and Compounds, 478 (2009) 269-272.

[29] K.G. Pradeep, N. Wanderka, P. Choi, J. Banhart, B.S. Murty, D. Raabe, Acta Materialia, $61(2013)$ 4696-4706.

[30] S.M.C. van Bohemen, Scripta Materialia, 69 (2013) 315-318.

[31] Y.S. Touloukian, R.K. Kirky, R.E. Taylor, P.D. Desai, Thermophysical Properties of Matter, Thermal Expansion: Metallic Elements and Alloys, TPRC Data Books, PlenumPress, NewYork, 1975.

[32] W. Köster, Zeitschrift für Metallkunde, 39 (1948) 1-9.

[33] P.E. Armstrong, H.L. Brown, Tansactions of the metallurgical society of AIME, 230 (1964) 962-966.

[34] A. Kagawa, T. Okamoto, H. Matsumoto, Acta Metallurgica, 35 (1987) 797-803.

[35] B.A. Latella, S.R. Humphries, Scripta Materialia, 51 (2004) 635-639.

[36] G. Frommeyer, R. Rablbauer, H.J. Schäfer, Intermetallics, 18 (2010) 299-305.

[37] G. Laplanche, P. Gadaud, J. Bonneville, A. Joulain, V. Gauthier-Brunet, S. Dubois, F. Jay, Journal of Materials Science, 47 (2012) 169-175.

[38] K. Tanaka, Y. Mitarai, M. Koiwa, Philosophical Magazine A, 73 (1996) 1715-1723.

[39] G. Laplanche, J. Bonneville, A. Joulain, V. Gauthier-Brunet, S. Dubois, Intermetallics, 50 (2014) 54-58.

[40] D. Siebörger, H. Knake, U. Glatzel, Materials Science and Engineering: A, 298 (2001) 26-33.

[41] P. Gadaud, Elastic Properties Characterization by Means of Dynamic Resonant Technique, in: N.M. Ranganathan (Ed.) Materials Characterization: Modern Methods and Applications, Pan Stanford, 2015. 
[42] Y.P. Varshni, Physical Review B, 2 (1970) 3952-3958.

[43] A.J. Zaddach, C. Niu, C.C. Koch, D.L. Irving, JOM, The Journal of The Minerals, Metals \& Materials Society (TMS) 65 (2013) 1780

[44] W. Köster, Zeitschrift für Metallkunde, 39 (1948) 145-158.

[45] W. Köster, Zeitschrift für Metallkunde, 39 (1948) 178-184. 


\section{Table}

Table 1. Chemical composition (in at.\%) of the CoCrFeMnNi HEA. The precision of the values are $0.02 \%$ and $0.005 \%$ for metallic and non-metallic elements, respectively.

\begin{tabular}{|l|l|l|l|l|l|l|l|}
\hline Co & $\mathrm{Cr}$ & $\mathrm{Fe}$ & $\mathrm{Mn}$ & $\mathrm{Ni}$ & $\mathrm{C}$ & $\mathrm{O}$ & $\mathrm{S}$ \\
\hline 20.26 & 19.41 & basis & 20.10 & 19.58 & 0.051 & 0.033 & 0.009 \\
\hline
\end{tabular}




\section{Figure Captions}

Fig. 1: Fully recrystallized CoCrFeMnNi high-entropy alloy (a) X-ray diffraction pattern showing FCC peaks, (b) inverse pole figure map, (c) to (e) (001), (011) and (111) pole figures, respectively.

Fig. 2: (a) Relative change in specimen length $\Delta L / L_{0}$ of the CoCrFeMnNi high-entropy alloy with temperature. (b) Coefficient of thermal expansion $\alpha$ as a function of temperature for the CoCrFeMnNi high-entropy alloy (red line) and FCC steels [30].

Fig. 3: (a) Young's modulus $E$ and shear modulus $G$ of the CoCrFeMnNi high-entropy alloy as a function of temperature. Black and red data points correspond to raw data and data corrected for thermal expansion effects according to standard test methods ATSM E1876-01. (b) Corrected E and $G$ measured in the present study between 200 and $1000 \mathrm{~K}$ (red curve) together with measurements between 55 and 300 K (blue curve) reported by Haglund et al. [20]. (c) Young's modulus $E$ as a function of temperature for the CoCrFeMnNi high-entropy alloy (red line) and for $\mathrm{Co}, \mathrm{Cr}, \mathrm{Fe}, \mathrm{Mn}$ and Ni pure metals. (d) Reduced Young's modulus vs reduced (homologous) temperature for the CoCrFeMnNi high-entropy alloy (red line) and for $\mathrm{Co}, \mathrm{Cr}, \mathrm{Fe}, \mathrm{Mn}$ and $\mathrm{Ni}$ pure metals. 

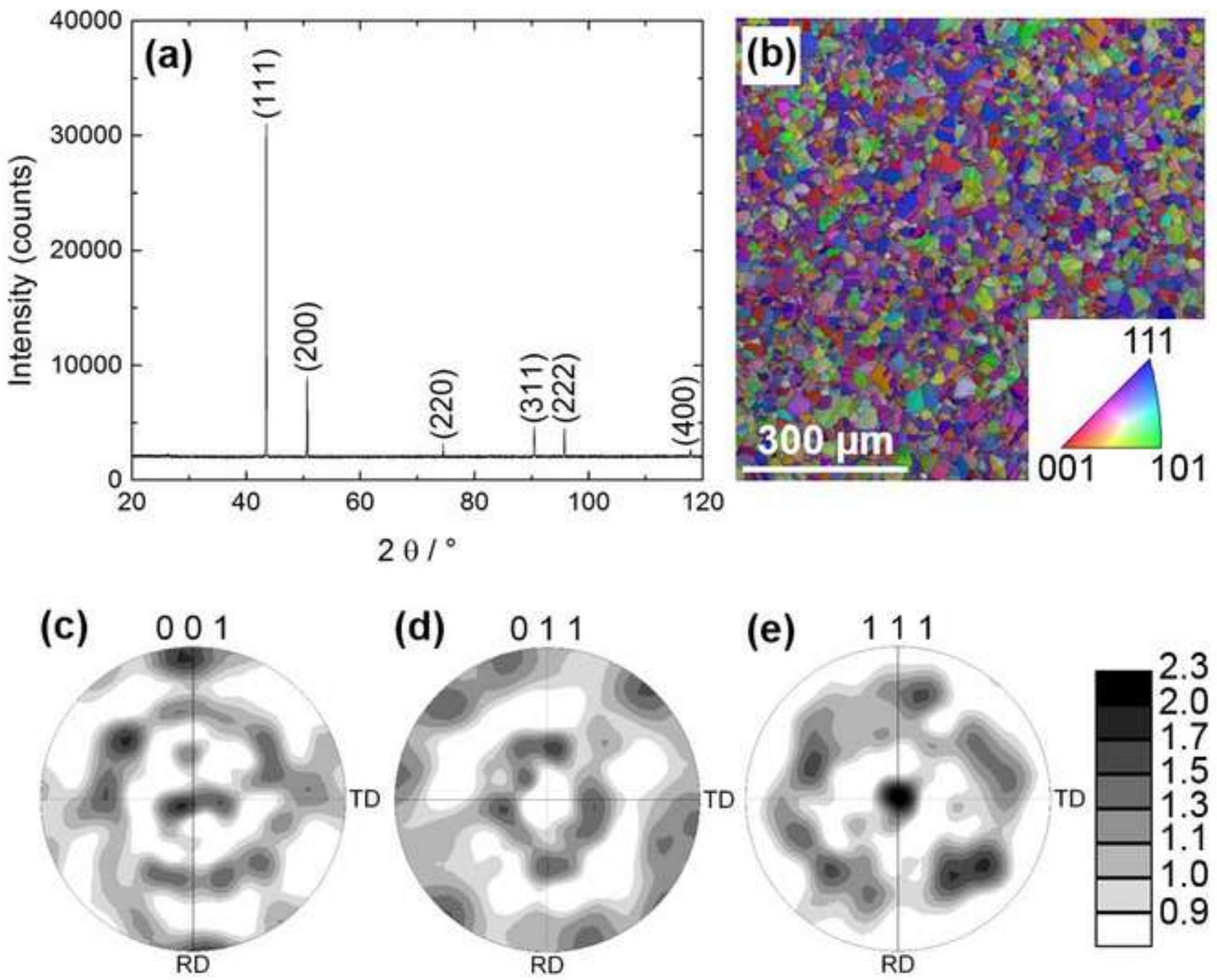
Figure
Click here to download high resolution image

Figure
Click here to download high resolution image

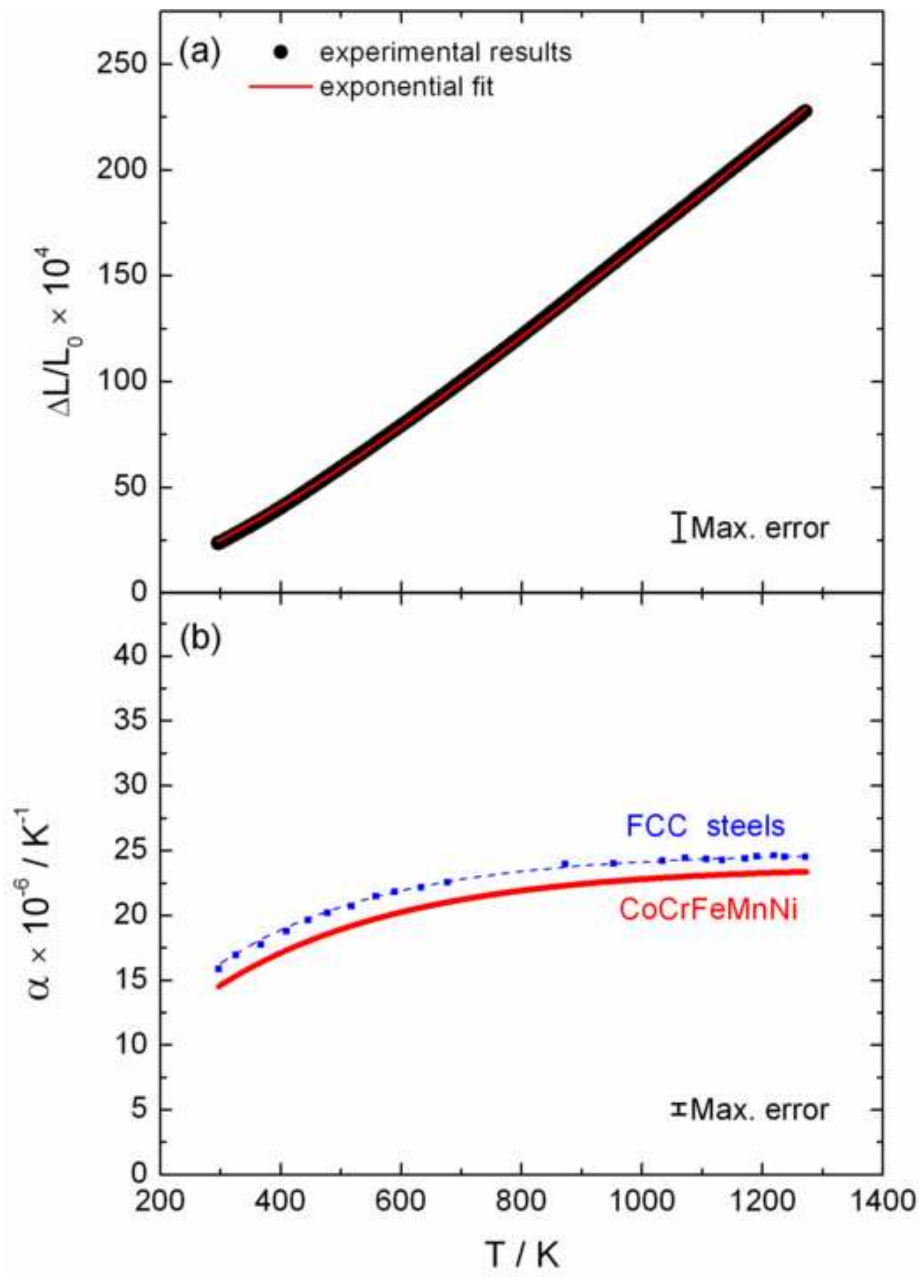

. 

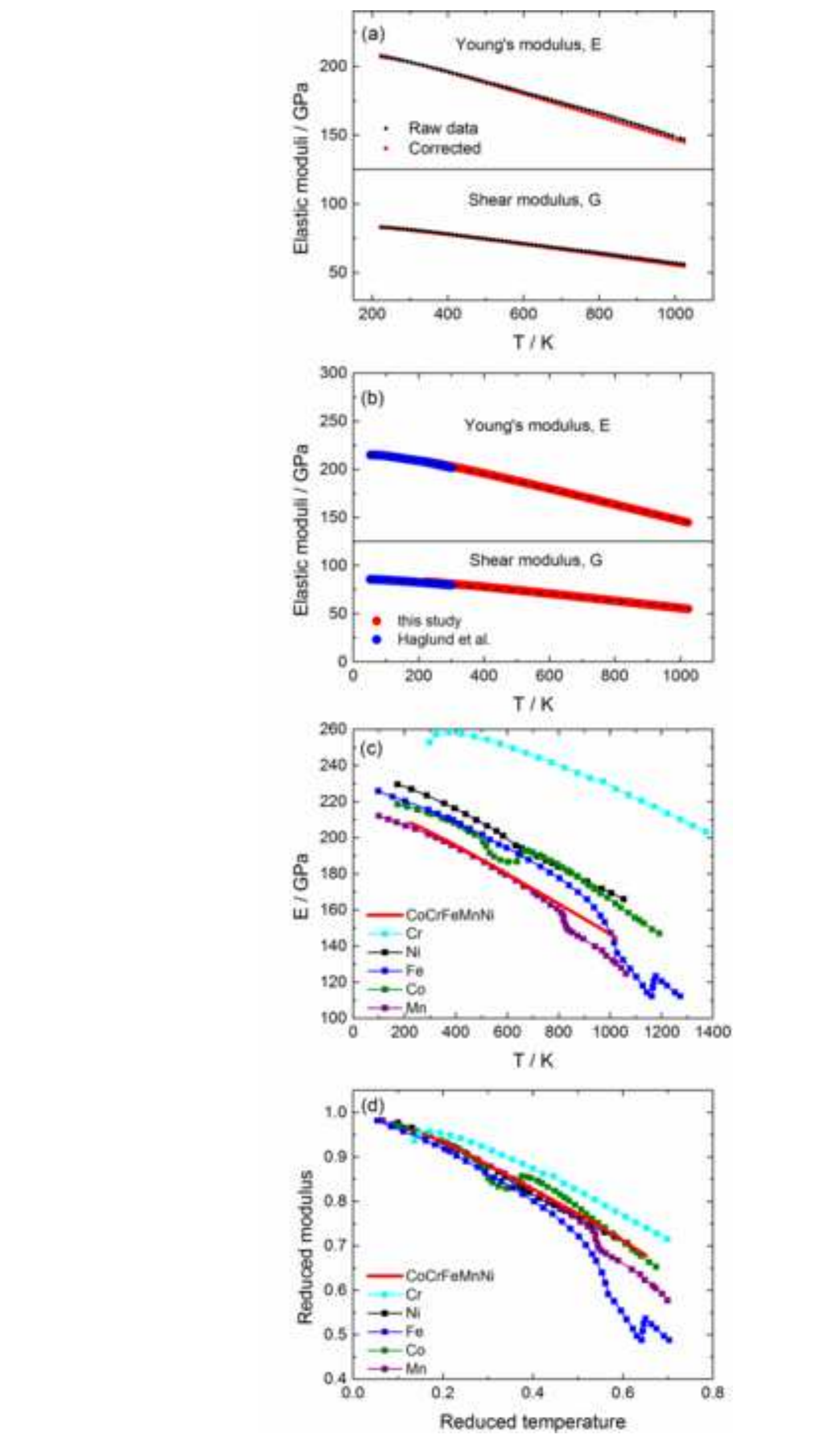

Figure
Click here to download high resolution image
rere

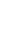

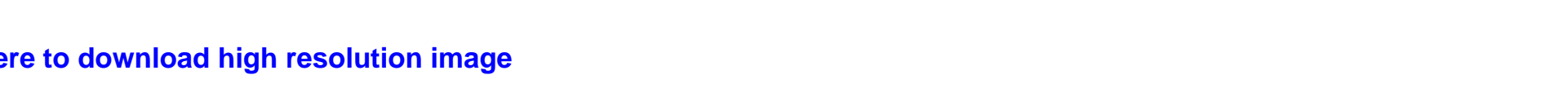

(1)

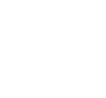

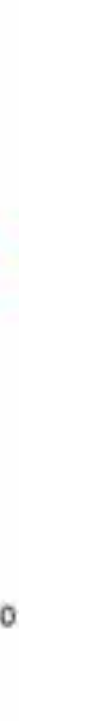

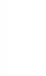

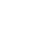

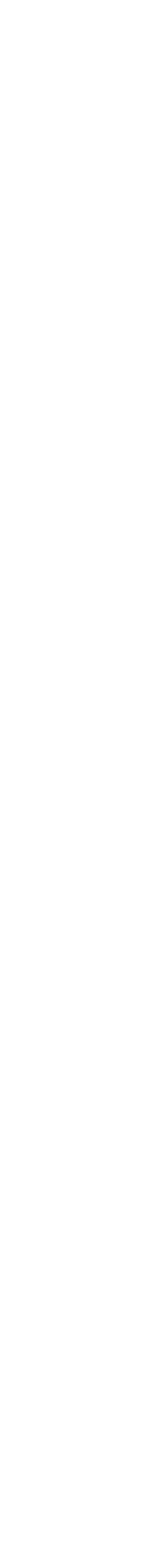

